Check for updates

Cite this: Nanoscale Adv., 2019, 1, 342

\title{
Performing a catalysis reaction on filter paper: development of a metal palladium nanoparticle- based catalyst $\uparrow$
}

\author{
Yili Zhao, ${ }^{\text {abc }}$ Lei Liu, ${ }^{a}$ Daniel Shi, ${ }^{a}$ Xiangyang Shi $(D)$ *a and Mingwu Shen (D) *a
}

We report the polyethylenimine (PEI)-mediated immobilization of palladium nanoparticles (Pd NPs) onto filter paper for catalytic applications. In this work, filter paper was first assembled with PEI via electrostatic interaction, and the $\mathrm{PEl}$-assembled filter paper was then complexed with $\mathrm{PdCl}_{4}{ }^{2-}$ ions, followed by sodium borohydride reduction to generate Pd NP-immobilized filter paper. Transmission electron microscopy reveals that Pd NPs have a diameter of $3 \mathrm{~nm}$ and are capable of being immobilized onto the filter paper. The Pd NP-immobilized filter paper exhibits remarkable catalytic activity and is reusable in the reductive transformation of $\mathrm{Cr}(\mathrm{VI})$ to $\mathrm{Cr}(\mathrm{III})$ and 4-nitrophenol to 4-aminophenol. The strategy used to develop Pd NPimmobilized filter paper could be adopted to generate other metal NP-immobilized filter papers for other applications such as sensing materials, energy, environmental remediation, and biomedical sciences.

Received 21st July 2018

Accepted 9th September 2018

DOI: $10.1039 / \mathrm{c} 8 \mathrm{na00095f}$

rsc.li/nanoscale-advances

\section{Introduction}

Tremendous scientific and technological interest has been raised by metallic nanoparticles (NPs) for catalytic applications $^{1-3}$ because of their huge surface area and distinctive surface electronic properties. ${ }^{4,5}$ Palladium NPs (Pd NPs), as one of the representatives, have been paid increasing attention owing to their intriguing properties and high catalytic activity. ${ }^{6,7}$ Colloidal Pd NPs have been widely used as catalysts, ${ }^{8-12}$ such as for the reduction of $\mathrm{Cr}(\mathrm{VI})$ to $\mathrm{Cr}(\mathrm{III})$, and 4-nitrophenol (4-NP) to 4 -aminophenol (4-AP). Cr(vi) is a common heavy metal contaminant due to its carcinogenic and mutagenic nature. In addition, it leads to liver damage, pulmonary congestion and causes skin irritation. Because $\mathrm{Cr}$ (III) plays an important role in sugar and fat metabolism, the reduction of $\mathrm{Cr}(\mathrm{VI})$ to $\mathrm{Cr}(\mathrm{III})$ is usually chosen as an effective method for the remediation of $\mathrm{Cr}(\mathrm{vI})$-contaminated water. ${ }^{13,14} 4$-NP generated from industrial effluent has been considered as the most toxic and refractory pollutant. It has been cited by the U.S. Environmental Protection Agency on the "Priority Pollutant List" due to the potential environmental and public health risks. ${ }^{15}$ The reduction of 4-NP

${ }^{a}$ Key Laboratory of Science and Technology of Eco-Textiles, Ministry of Education, College of Chemistry, Chemical Engineering and Biotechnology, Donghua University, Shanghai 201620, People's Republic of China.E-mail: mwshen@dhu.edu.cn; xshi@ dhu.edu.cn

${ }^{b}$ Zhejiang Provincial Key Laboratory of Fiber Materials and Manufacturing Technology, College of Materials and Textiles, Zhejiang Sci-Tech University, Hangzhou, 310018, People's Republic of China

${ }^{c}$ State Key Laboratory of Molecular Engineering of Polymers, Fudan University, Shanghai 200433, People's Republic of China

$\dagger$ Electronic supplementary information (ESI) available. See DOI: 10.1039/c8na00095f to 4-AP has been intensively investigated because of the fact that the produced 4-AP is an important intermediate for the manufacture of chemicals and drugs. ${ }^{16}$ However, the practical catalytic applications of Pd NPs in solutions are limited owing to their colloidal stability issues and recyclability. The general approach to overcome such shortcomings is to immobilize metallic NPs onto different types of solid matrices such as fibers, ${ }^{17-19}$ clays, ${ }^{20}$ membranes, ${ }^{21}$ porous solids, ${ }^{22,23}$ graphenes $^{24-28}$ and functionalized nanobeads. ${ }^{29}$

Commercial filter paper possesses many unique features such as high porosity, good flexibility, robust mechanical durability, and chemical stability. ${ }^{30}$ Furthermore, filter paper with cellulose as a major component can be easily modified due to the fact that cellulose is an oxygen-rich natural polymer, ${ }^{31}$ and the porous structure and microfibrils of the filter paper are amenable for metal NPs to be anchored. ${ }^{32}$ Hence, filter paper has been ideally used to immobilize $\mathrm{Au},{ }^{33,34} \mathrm{Ag}^{35}{ }^{35} \mathrm{Fe},{ }^{36} \mathrm{Ni}^{37,38} \mathrm{Cu}^{39}$ and Pd NPs. ${ }^{40,41}$ For catalytic applications, Xu et al. ${ }^{42}$ immobilized Pd NPs onto cellulose fibers, but the process required long impregnation time $(72 \mathrm{~h})$ and high reaction temperature $\left(60^{\circ} \mathrm{C}\right)$ to obtain high loading efficiency. Zheng et al. ${ }^{40}$ fabricated Pd NP-loaded filter paper with a high catalytic efficiency and recyclability by a dipcoating process. However, the method employed to create Pd NPs was rather complicated and one has to use toxic organic solvents under high temperatures.

Previously, we have shown that $\mathrm{Au},{ }^{43,44} \mathrm{Au} / \mathrm{Ag},{ }^{18} \mathrm{Fe},{ }^{45-48} \mathrm{Fe} / \mathrm{Ni},{ }^{49}$ and $\mathrm{Fe} / \mathrm{Pd} \mathrm{NPs}^{50}$ could be synthesized in situ and immobilized onto or within polymer nanofibers formed via electrospinning. We also demonstrated that Pd NPs can be in situ synthesized and embedded within electrospun polyethylenimine (PEI)/polyvinyl alcohol (PVA) nanofibers. ${ }^{51}$ In addition, branched PEI was adopted as either a template or stabilizer to prepare metal 


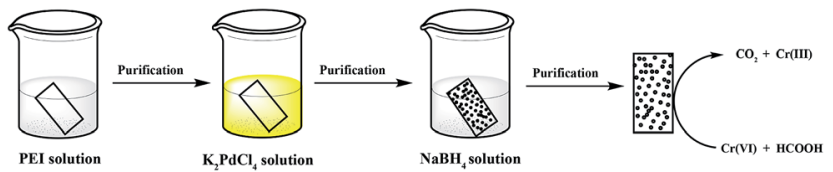

Scheme 1 Schematic illustration of the immobilization of Pd NPs onto filter paper for catalytic applications.

NPs. ${ }^{52-54}$ These earlier investigations associated with electrospun nanofibers immobilized with metal NPs prompted us to hypothesize that Pd NPs could also be immobilized onto filter paper through the assembly of PEI and the PEI-mediated in situ synthesis method.

In this paper, we present an in situ method to immobilize Pd NPs onto filter paper for subsequent applications as a catalyst. A piece of filter paper was first soaked into a PEI aqueous solution, followed by rinsing with water. Then, the PEI-assembled filter paper was dipped into a $\mathrm{K}_{2} \mathrm{PdCl}_{4}$ aqueous solution, rinsed with water, and the $\mathrm{PdCl}_{4}{ }^{2-}$ adsorbed onto the PEI-modified filter paper was reduced to Pd NPs by sodium borohydride $\left(\mathrm{NaBH}_{4}\right)$. The generated filter paper containing Pd NPs was characterized via different technologies. We then tested the catalytic performance and reusability of the formed Pd NP-immobilized filter paper through reactions transforming $\mathrm{Cr}$ (VI) to $\mathrm{Cr}$ (III) (Scheme 1) and converting 4-NP to 4-AP. According to a thorough literature exploration, currently there are no similar studies using PEI to form Pd NP-immobilized filter paper for catalytic applications.

\section{Experimental}

\section{Preparation of the Pd NP-immobilized filter paper}

The process shown in Scheme 1 is the process of fabricating the Pd NP-containing filter paper. First, a piece of filter paper $(1 \times 2$ $\mathrm{cm}^{2}, 18 \mathrm{mg}$ and pore size: $\left.15-20 \mu \mathrm{m}\right)$ was dipped into a PEI solution (20 $\mathrm{mgmL}^{-1}$ and $5 \mathrm{~mL}$ in water) for $5 \mathrm{~min}$ and rinsed with water 3 times to eliminate excess PEI. Then the PEImodified filter paper was dipped into a $\mathrm{K}_{2} \mathrm{PdCl}_{4}$ solution (13 $\mathrm{mgmL}^{-1}, 5 \mathrm{~mL}$ in water) for $5 \mathrm{~min}$ and was thoroughly rinsed. The filter paper was then immersed into a $\mathrm{NaBH}_{4}$ solution (8 $\mathrm{mgmL}^{-1}, 5 \mathrm{~mL}$ in water) for $10 \mathrm{~min}$ to reduce the complexed $\mathrm{PdCl}_{4}{ }^{2+}$ ions. Finally, the formed filter paper containing Pd NPs was washed with copious water, vacuum dried at room temperature, and stored in a desiccator.

\section{Catalysis experiments}

We performed the transformation of $\mathrm{Cr}(\mathrm{VI})$ to $\mathrm{Cr}(\mathrm{III})^{38,42}$ and 4-NP to $4-\mathrm{AP}^{44}$ to assess the efficiency and reusability of the Pd NPimmobilized filter paper as a catalyst. ${ }^{51,55}$ The details are described in the ESI. $\dagger$

\section{Results and discussion}

\section{Preparation and characterization of the filter paper containing the immobilized Pd NPs}

In this study, we immobilized Pd NPs onto the surface of the filter paper via the PEI-mediated in situ reduction of $\mathrm{PdCl}_{4}{ }^{2-}$ ions. First, PEI was adsorbed onto the filter paper through electrostatic interaction, and then $\mathrm{PdCl}_{4}{ }^{2-}$ was adsorbed onto PEI by coordination interaction. Finally, $\mathrm{PdCl}_{4}{ }^{2-}$ was reduced to form Pd NPs using $\mathrm{NaBH}_{4}$. The filter paper became quite brown after the formation of Pd NPs (Fig. S1, ESI $\dagger$ ), verifying the success of the formation of Pd NPs.

The morphology of the Pd NP-loaded filter paper was then visualized by SEM (Fig. 1). As opposed to the Pd-free filter paper, the Pd NP-loaded filter paper shows some particles on the surface of cellulose fibers, indicating the success of the immobilization of Pd NPs onto the filter paper. Further, it seemed that the Pd NPs were well dispersed onto the cellulose fiber surface. The immobilization of the Pd NPs onto the filter paper was also confirmed by EDS (Fig. S2, ESI $\dagger$ ), where the signal of Pd is apparent.

TEM was employed to observe the distribution of Pd NPs on the filter paper. From the cross-sectional TEM image (Fig. 2a), it can be observed that the Pd NPs are dispersed along the cellulose fiber surface of the filter paper. The Pd NPs exhibit an elliptical shape with a quite narrow size distribution (Fig. 2b). The average diameter of the Pd NPs was measured to be $3.0 \pm$ $0.9 \mathrm{~nm}$ (Fig. 2c), which is smaller than that of Pd NPs $(6.2 \pm$ $1.5 \mathrm{~nm}$ ) formed by in situ reduction. ${ }^{56}$ This suggests that PEI assembled onto the filter paper is capable of limiting the growth of Pd NPs.

TGA was adopted to quantify the percentage of Pd NPs loaded onto the filter paper (Fig. S3, ESI $\dagger$ ). The slight initial loss of weight for the filter paper without and with Pd NPs is likely to be attributed to the moisture loss in the samples, while the weight loss of the Pd NP-loaded filter paper is associated with the decomposition of the filter paper and PEI in the region of 300-800 ${ }^{\circ} \mathrm{C}$. Compared with the filter paper without the loaded Pd NPs (Fig. S3, ESI, †curve a), the percentage of Pd NPs loaded onto the filter paper was estimated to be $1.1 \%$ (Fig. S3, ESI, $\uparrow$ curve b). To further quantify the Pd loading percentage onto the filter paper, ICP-OES analysis was performed. The Pd concentration tested by ICP-OES was $12.5052 \mathrm{ppm}$, and the Pd loading percentage was calculated to be $1.0 \%$, corroborating the TGA results.

\section{Catalytic transformation of $\mathrm{Cr}(\mathrm{VI})$ to $\mathrm{Cr}(\mathrm{III})$}

The catalytic activity of the Pd NP-immobilized filter paper was estimated by converting $\mathrm{Cr}(\mathrm{VI})$ to $\mathrm{Cr}(\mathrm{III})$. The catalytic mechanism of Pd NPs can be explained as follows: (1) formic acid is first adsorbed onto the surface of Pd NPs, and then decomposed to form $\mathrm{H}_{2}$ and $\mathrm{CO}_{2}$; (2) $\mathrm{Cr}(\mathrm{VI})$ is reduced to $\mathrm{Cr}(\mathrm{III})$ by the formed
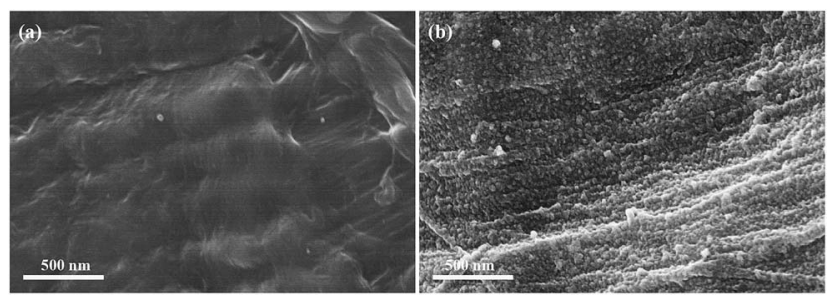

Fig. 1 SEM images of the filter paper without (a) and with (b) the immobilized Pd NPs. 


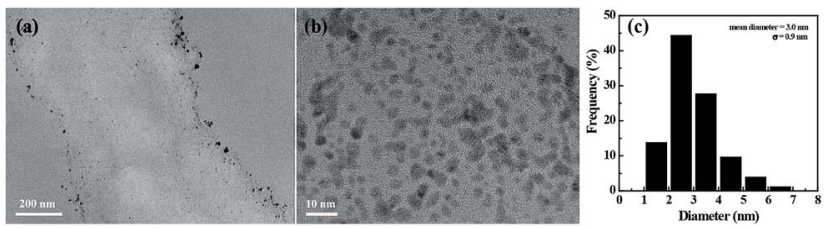

Fig. 2 Cross-sectional TEM image (a) and high-resolution TEM image (b) of the Pd NP-loaded filter paper. (c) Diameter distribution histogram of the formed Pd NPs.

$\mathrm{H}_{2}$ adsorbed onto the surface of Pd NPs. ${ }^{57}$ The amine groups on the surface of Pd NPs favor the decomposition of the $\mathrm{O}-\mathrm{H}$ bond in formic acid dehydrogenation due to the amine grouprendered basic environment. ${ }^{58,59}$ We confirmed the catalytic activity of the filter paper immobilized with Pd NPs first by the gradual color change of the reaction solution. The color fading from yellow to colorless within 28 min showcased the effective transformation of $\mathrm{Cr}$ (VI) to $\mathrm{Cr}$ (III) (Fig. S4b, ESI †). In contrast, the Pd-free filter paper treated with $\mathrm{K}_{2} \mathrm{Cr}_{2} \mathrm{O}_{7}$ solution did not display any apparent color change (Fig. S4a, ESI $\dagger$ ). In addition, a decrease in the characteristic absorbance of $\mathrm{Cr}_{2} \mathrm{O}_{7}{ }^{2-}$ at $350 \mathrm{~nm}$ with time (Fig. $3 \mathrm{~b}$ ) also validated the process of the reduction reaction. The catalytic activity of the Pd NPimmobilized filter paper was calculated to be $98 \%$ at $28 \mathrm{~min}$. In comparison, the catalytic efficiency of Pd-activated carbon was $91.6 \%$ at $12 \mathrm{~min}$ and $94.2 \%$ at $28 \mathrm{~min}$ (Fig. 4). This means that Pd-activated carbon could catalyze the conversion of $\mathrm{Cr}(\mathrm{vI})$ to $\mathrm{Cr}$ (III) quickly, but the catalytic efficiency at $28 \mathrm{~min}$ was slightly lower than that of the Pd-immobilized filter paper. In addition, the biggest drawback of Pd-activated carbon is that it is difficult to recover it for the next round of catalytic reactions. In contrast, the Pd NP-immobilized filter paper can be easily recovered and used for at least 3 times (see below).

To further prove the existence of $\mathrm{Cr}(\mathrm{III})$ in the final reaction solution, we added excess sodium hydroxide solution to the reaction mixture. The colorless solution quickly changed to green, implying the generation of hexahydroxochromate(III). ${ }^{55,60}$ In the control experiment, the Pd-free filter paper was used to catalyze the transformation of $\mathrm{Cr}(\mathrm{vI})$ to $\mathrm{Cr}(\mathrm{III})$. The absorption of $\mathrm{Cr}(\mathrm{vI})$ at $350 \mathrm{~nm}$ showed just a little change over $28 \mathrm{~min}$ (Fig. 3a). These data further supported that the powerful catalytic activity was associated with the Pd NPs immobilized onto the filter
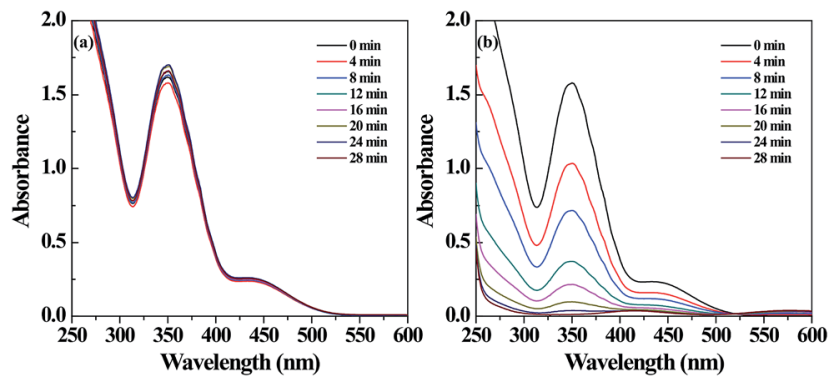

Fig. 3 UV-vis spectra of the $\mathrm{Cr}(\mathrm{VI})$ solution treated with filter paper without (a) and with (b) Pd NPs loaded at different time intervals.

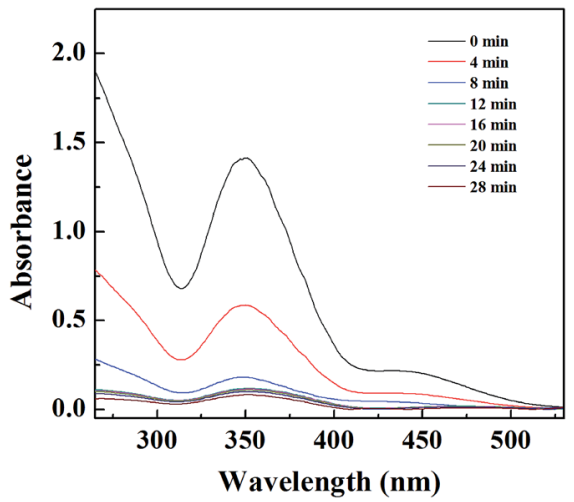

Fig. 4 UV-vis spectra of the $\mathrm{Cr}(\mathrm{VI})$ solution treated with $\mathrm{Pd}$-activated carbon at different time intervals.

paper. The catalytic activity of the Pd NP-loaded filter paper may not be comparable to that of the Pd NPs loaded within the electrospun PAA/PVA nanofibrous mats ${ }^{51}$ due to the loading capacity and fiber structure of the materials. However, the adopted materials of filter paper and the PEI polymer are sustainable and quite cost-effective, and the immobilization procedure is quite simple. Therefore, the prepared Pd NPloaded filter paper may be rather adaptable to industrial use.

The reusability of a catalyst is crucial for practical applications, especially for noble metals. To test the reusability of the Pd NP-immobilized filter paper, the filter paper was rinsed with water and dried for the next round of reaction. By plotting the remaining fraction of $\mathrm{Cr}(\mathrm{vI})$ versus reaction time, we compared the catalytic activity of the filter paper containing Pd NPs. Clearly, more than $98 \%$ of $\mathrm{Cr}(\mathrm{VI})$ can be converted to $\mathrm{Cr}(\mathrm{III})$ within $28 \mathrm{~min}$ for three reaction cycles (Fig. 5), validating the remarkable reusability of the Pd NP-immobilized filter paper. It is worth mentioning that the Pd NPs loaded onto the filter paper were stable and were not released during the reaction. This was proven by ICP-OES analysis, showing that no Pd content was detectable in the reaction mixture even after 3 cycles of catalytic reaction.

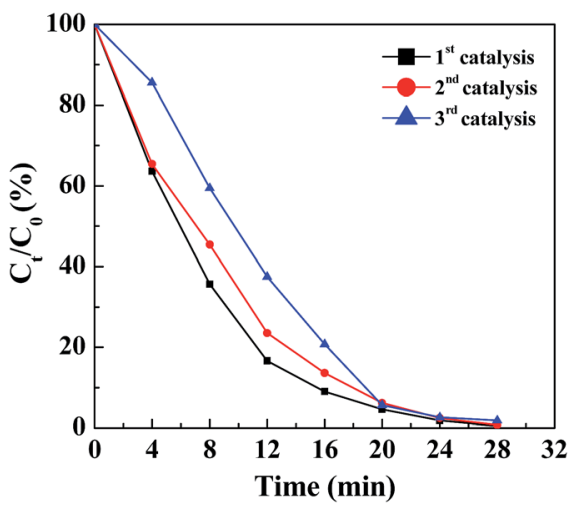

Fig. 5 Remaining fraction of $\mathrm{Cr}(\mathrm{VI})$ as a function of time in the presence of the Pd NP-loaded filter paper for the first, second and third cycle of catalytic reaction. 

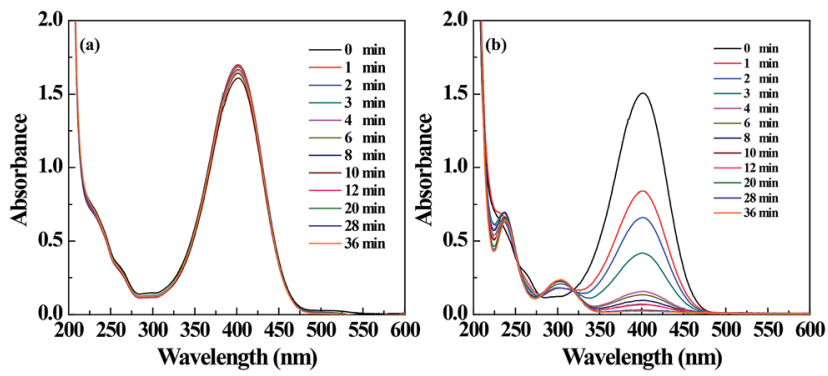

Fig. 6 UV-vis spectra of the 4-NP solution treated with the filter paper without (a) and with (b) Pd NPs loaded at different time intervals.

\section{Catalytic conversion of 4-NP to 4-AP}

The catalytic property of the filter paper containing Pd NPs was also tested by a model reaction converting 4-NP to 4-AP. By immersing ordinary Pd-free filter paper into the reaction mixture, we did not see the color change of 4-NP solution (Fig. S5a, ESI $\dagger$ ), and the absorption peak of 4-NP at $400 \mathrm{~nm}$ just slightly decreased within 36 min (Fig. 6a). This is likely attributed to the intrinsic physical adsorption of 4-NP onto the filter paper. It demonstrates that the Pd-free filter paper has no catalytic activity. In contrast, when the Pd NP-loaded filter paper was used, gradual color fading of the 4-NP solution occurred (Fig. S5b, ESI $\dagger$ ). This can also be reflected by the gradual decrease of the absorbance of $4-\mathrm{NP}$ at $400 \mathrm{~nm}$ and gradual emergence of a new peak at $300 \mathrm{~nm}$, suggesting the formation of 4-AP (Fig. 6b). Around 95\% of 4-NP can be converted to 4-AP within $10 \mathrm{~min}$, implying that the Pd NP-loaded filter paper can efficiently catalyze the reduction reaction.

Although colloidal Pd NPs have a high catalytic ability to catalyze the conversion of 4-NP to 4-AP, the colloidal Pd NPs suffer from recycling difficulty for further use. We also tested the reusability of the Pd NP-loaded filter paper. We can see that more than $98 \%$ of $4-\mathrm{NP}$ is transformed to 4 -AP within $36 \mathrm{~min}$ even at the fourth cycle of the catalytic reaction, demonstrating the reusability of the Pd NP paper (Fig. S6, ESI†). The slightly decreased catalytic activity of the Pd NP paper is likely owing to the swelling of the cellulose fibers during the reaction, thereby slightly affecting the access of 4-NP to the Pd NPs loaded inside the pores of the cellulose fibrils. This can also be applied to explain the slight decrease of the catalytic activity in the conversion of $\mathrm{Cr}(\mathrm{VI})$ to $\mathrm{Cr}(\mathrm{III})$ during reuses. In addition, the $\mathrm{Pd}$ NPs loaded onto the filter paper showed no appreciable release into the reaction solution, which can be further confirmed by ICP-OES analysis, where no Pd content could be detected even after 4 cycles of reaction.

\section{Conclusions}

We present a convenient, time-saving, cost-effective, and sustainable approach to immobilizing Pd NPs onto filter paper via PEI-mediated in situ reduction of $\mathrm{PdCl}_{4}{ }^{2-}$. The porous filter paper can be immobilized with Pd NPs with a Pd core size of $3.0 \mathrm{~nm}$ and Pd loading percentage of $1.1 \%$. The Pd NP-loaded filter paper can be adopted to catalyze the conversion of $\mathrm{Cr}(\mathrm{vI})$ to $\mathrm{Cr}$ (III) with an efficiency of $98 \%$ within $28 \mathrm{~min}$ and 4 -NP to 4 AP with an efficiency of $98 \%$ within 36 min with an excellent reusability. Such a strategy to immobilize Pd NPs onto filter paper may be applicable to immobilize other metal or metal oxide NPs onto filter paper for a range of applications.

\section{Conflicts of interest}

There are no conflicts to declare.

\section{Acknowledgements}

Financial support from the Fundamental Research Funds for the Central Universities (M. Shen and X. Shi), "111 Project" (B07024), and the Science and Technology Commission of Shanghai Municipality (15520711400 and 17540712000) are greatly acknowledged. Y. Zhao thanks the Foundation of Zhejiang Educational Committee (No. Y201636691) and the Science Foundation of Zhejiang Sci-Tech University (ZSTU) under Grant No. 16012089-Y. Daniel Shi is a student from the International Division of No. 2 High School of East China Normal University working during the summer.

\section{Notes and references}

1 P. Herves, M. Perez-Lorenzo, L. M. Liz-Marzan, J. Dzubiella, Y. Lu and M. Ballauff, Chem. Soc. Rev., 2012, 41, 5577-5587.

2 K. An and G. A. Somorjai, Catal. Lett., 2015, 145, 233-248.

3 W. H. Eisa, A. M. Abdelgawad and O. J. Rojas, ACS Sustainable Chem. Eng., 2018, 6, 3974-3983.

4 M. Pelton, J. Aizpurua and G. Bryant, Laser Photonics Rev., 2008, 2, 136-159.

5 H. J. Yin, S. L. Zhao, K. Zhao, A. Muqsit, H. J. Tang, L. Chang, H. J. Zhao, Y. Gao and Z. Y. Tang, Nat. Commun., 2015, 6, 6430.

6 F. Wang, C. H. Li, L. D. Sun, C. H. Xu, J. F. Wang, J. C. Yu and C. H. Yan, Angew. Chem., Int. Ed., 2012, 51, 4872-4876.

7 M. T. Zhao, K. Deng, L. C. He, Y. Liu, G. D. Li, H. J. Zhao and Z. Y. Tang, J. Am. Chem. Soc., 2014, 136, 1738-1741.

8 A. Balanta, C. Godard and C. Claver, Chem. Soc. Rev., 2011, 40, 4973-4985.

9 W. X. Tu, K. J. Li, X. H. Shu and W. W. Yu, J. Nanopart. Res., 2013, 15, 1593-1602.

10 J. Gu, C. S. Hu, W. W. Zhang and A. Dichiara, Appl. Catal., B, 2018, 237, 482-490.

11 M. Rezayat, R. K. Blundell, J. E. Camp, D. A. Walsh and W. Thielemans, ACS Sustainable Chem. Eng., 2014, 2, 12411250.

12 X. D. Wu, C. H. Lu, W. Zhang, G. P. Yuan, R. Xiong and X. X. Zhang, J. Mater. Chem. A, 2013, 1, 8645-8652.

13 P. Miretzky and A. F. Cirelli, J. Hazard. Mater., 2010, 180, 119.

14 W. Liu, J. Ni and X. Yin, Water Res., 2014, 53, 12-25.

15 K. B. Narayanan and N. Sakthivel, J. Hazard. Mater., 2011, 189, 519-525.

16 J. Li, C. Y. Liu and Y. Liu, J. Mater. Chem., 2012, 22, 84268430 . 
17 H. C. Mu, C. P. Li, J. Bai and W. Y. Sun, J. Mol. Struct., 2018, 1165, 90-100.

18 D. M. Hu, Y. C. Xiao, H. Liu, H. Wang, J. C. Li, B. Q. Zhou, P. C. Liu, M. W. Shen and X. Y. Shi, Colloids Surf., A, 2018, 552, 9-15.

19 Z. Y. Xiang, Y. Chen, Q. G. Liu and F. C. Lu, Green Chem., 2018, 20, 1085-1094.

20 Y. Ma and G. K. Zhang, Chem. Eng. J., 2016, 288, 70-78.

21 E. Hariprasad and T. P. Radhakrishnan, ACS Catal., 2012, 2, 1179-1186.

22 S. Y. Oh, J. Kim and Y. Kim, Mater. Lett., 2015, 154, 60-63.

23 E. Petala, K. Dimos, A. Douvalis, T. Bakas, J. Tucek, R. Zboril and M. A. Karakassides, J. Hazard. Mater., 2013, 261, 295306.

24 W. H. Dong, S. S. Cheng, C. Feng, N. Z. Shang, S. T. Gao and C. Wang, Catal. Commun., 2017, 90, 70-74.

25 S. Navalon, A. Dhakshinamoorthy, M. Alvaro and H. Garcia, Coord. Chem. Rev., 2016, 312, 99-148.

26 L. Shang, T. Bian, B. Zhang, D. Zhang, L. Z. Wu, C. H. Tung, Y. Yin and T. Zhang, Angew. Chem., 2014, 53, 250-254.

27 H. J. Yin, H. J. Tang, D. Wang, Y. Gao and Z. Y. Tang, ACS Nano, 2012, 6, 8288-8297.

28 H. J. Yin, S. L. Zhao, J. W. Wan, H. J. Tang, L. Chang, L. C. He, H. J. Zhao, Y. Gao and Z. Y. Tang, Adv. Mater., 2013, 25, 62706276.

29 R. Linhardt, Q. M. Kainz, R. N. Grass, W. J. Stark and O. Reiser, RSC Adv., 2014, 4, 8541-8549.

30 E. W. Nery and L. T. Kubota, Anal. Bioanal. Chem., 2013, 405, 7573-7595.

31 Y. Habibi, L. A. Lucia and O. J. Rojas, Chem. Rev., 2010, 110, 3479-3500.

32 L. Polavarapu and L. M. Liz-Marzan, Phys. Chem. Chem. Phys., 2013, 15, 5288-5300.

33 T. Niu, J. B. Xu, W. Xiao and J. G. Huang, $R S C A d v ., 2014,4$, 4901-4904.

34 G. C. Zheng, L. Polavarapu, L. M. Liz-Marzan, I. PastorizaSantos and J. Perez-Juste, Chem. Commun., 2015, 51, 45724575 .

35 S. Ashraf, R. Saifur, F. Sher, Z. M. Khalid, M. Mehmood and I. Hussain, Cellulose, 2014, 21, 395-405.

36 K. K. R. Datta, E. Petala, K. J. Datta, J. A. Perman, J. Tucek, P. Bartak, M. Otyepka, G. Zoppellaro and R. Zboril, Chem. Commun., 2014, 50, 15673-15676.

37 T. Kamal, S. B. Khan and A. M. Asiri, Environ. Pollut., 2016, 218, 625-633.

38 G. Bodelon, S. Mourdikoudis, L. Yate, I. Pastoriza-Santos, J. Perez-Juste and L. M. Liz-Marzan, ACS Nano, 2014, 8, 6221-6231.

39 T. Kamal, S. B. Khan and A. M. Asiri, Cellulose, 2016, 23, 1911-1923.
40 G. C. Zheng, K. Kaefer, S. Mourdikoudis, L. Polavarapu, B. Vaz, S. E. Cartmell, A. Bouleghlimat, N. J. Buurma, L. Yate, A. R. de Lera, L. M. Liz-Marzan, I. Pastoriza-Santos and J. Perez-Juste, J. Phys. Chem. Lett., 2014, 6, 230-238.

41 T. Nishikata, H. Tsutsumi, L. Gao, K. Kojima, K. Chikama and H. Nagashima, Adv. Synth. Catal., 2014, 356, 951-960.

42 Y. Xu, L. Zhang and Y. C. Cui, J. Appl. Polym. Sci., 2008, 110, 2996-3000.

43 X. fang, H. Ma, S. L. Xiao, M. W. Shen, R. Guo, X. Y. Cao and X. Y. Shi, J. Mater. Chem., 2011, 21, 4493-4501.

44 D. M. Hu, Y. P. Huang, H. Liu, H. Wang, S. G. Wang, M. W. Shen, M. F. Zhu and X. Y. Shi, J. Mater. Chem. A, 2014, 2, 2323-2332.

45 S. L. Xiao, M. W. Shen, R. Guo, Q. G. Huang, S. Y. Wang and X. Y. Shi, J. Mater. Chem., 2010, 20, 5700-5708.

46 S. L. Xiao, H. Ma, M. W. Shen, S. Y. Wang, Q. G. Huang and X. Y. Shi, Colloids Surf., A, 2011, 381, 48-54.

47 S. L. Xiao, M. W. Shen, R. Guo, S. Y. Wang and X. Y. Shi, J. Phys. Chem. C, 2009, 113, 18062-18068.

48 S. L. Xiao, S. Q. Wu, M. W. Shen, R. Guo, Q. G. Huang, S. Y. Wang and X. Y. Shi, ACS Appl. Mater. Interfaces, 2009, 1, 2848-2855.

49 H. Ma, Y. P. Huang, M. W. Shen, D. M. Hu, H. Yang, M. F. Zhu, S. P. Yang and X. Y. Shi, RSC Adv., 2013, 3, 6455-6465.

50 H. Ma, Y. P. Huang, M. W. Shen, R. Guo, X. Y. Cao and X. Y. Shi, J. Hazard. Mater., 2012, 211-212, 349-356.

51 Y. P. Huang, H. Ma, S. G. Wang, M. W. Shen, R. Guo, X. Y. Cao, M. F. Zhu and X. Y. Shi, ACS Appl. Mater. Inter., 2012, 4, 3054-3061.

52 B. Q. Zhou, M. W. Shen, I. Bányai and X. Y. Shi, Analyst, 2016, 141, 5390-5397.

53 B. Q. Zhou, J. Yang, C. Peng, J. Z. Zhu, Y. Q. Tang, X. Y. Zhu, M. W. Shen, G. X. Zhang and X. Y. Shi, Colloids Surf., B, 2016, 140, 489-496.

54 B. Q. Zhou, L. F. Zheng, C. Peng, D. Li, J. C. Li, S. H. Wen, M. W. Shen, G. X. Zhang and X. Y. Shi, ACS Appl. Mater. Interfaces, 2014, 6, 17190-17199.

55 M. A. Omole, I. O. K'Owino and O. A. Sadik, Appl. Catal., B, 2007, 76, 158-167.

56 J. H. He, T. Kunitake and A. Nakao, Chem. Mater., 2003, 15, 4401-4406.

57 G. T. Fu, X. Jiang, R. Wu, S. H. Wei, D. M. Sun, Y. W. Tang, T. H. Lu and Y. Chen, ACS Appl. Mater. Interfaces, 2014, 6, 22790-22795.

58 M. Yadav, T. Akita, N. Tsumori and Q. Xu, J. Mater. Chem., 2012, 22, 12582-12586.

59 K. Mori, M. Dojo and H. Yamashita, ACS Catal., 2013, 3, 1114-1119.

60 A. Dandapat, D. Jana and G. De, Appl. Catal., A, 2011, 396, 34-39. 